\title{
BEHAVIOUR OF VERTICAL CYLINDRICAL TANK WITH LOCAL WALL IMPERFECTIONS
}

\author{
Antanas ŠAPALAS ${ }^{1}$, Gintas ŠAUČIUVĖNAS ${ }^{1 *}$, Konstantin RASIULIS ${ }^{1}$, \\ Mečislovas GRIŠKEVIČIUS ${ }^{2}$, Tomas GEČYS ${ }^{1}$ \\ ${ }^{1}$ Department of Steel and Composite Structure, Faculty of Civil Engineering, \\ Vilnius Gediminas Technical University, Sauletekio al. 11, LT-10223 Vilnius, Lithuania \\ ${ }^{2}$ Department of Building Materials and Fire Safety Structure, Faculty of Civil Engineering, \\ Vilnius Gediminas Technical University, Sauletekio al. 11, LT-10223 Vilnius, Lithuania
}

Received 23 October 2018; accepted 19 February 2019

\begin{abstract}
Design of modern thin-walled metal structures is widely used around the world. In recent decades, more comprehensive research is carried out to investigate the behaviour of various thin-walled structures. Generally, the structure with regular geometry is investigated. In various countries such as USA, Russia, and the European Union issued the standards on regulation of the construction, design and maintenance of thin-walled structures.

The actually used period of tanks usually is longer than recommendatory period. Recommendatory maintenance period of metal tanks is 15-20 years. Therefore, for such structures one of the most considerable questions is the residual load bearing capacity beyond the end of the maintenance period. This phase of using of structures is associated with complex investigation and numerical analysis of thin-walled structures.

In this paper the load bearing capacity of the steel wall of the existing over-ground vertical cylindrical tank in volume of $5,000 \mathrm{~m}^{3}$ with a single defect and with a few contiguous local defects of the shape is analyzed. Calculations carried out are taking into account all the imperfections of the wall geometry.

A major goal of the research - developing a realistic numerical model of the object analyzed, taking into account all the imperfections, determining the wall stress and strain state, exploring the places of extreme points, calculating the residual load bearing capacity of the tank and scrutinizing possible strengthening schemes for defective areas.
\end{abstract}

Keywords: tank, imperfection, stress concentration factor, strengthening, crash.

\section{Introduction}

The construction and design methods of aboveground metal vertical cylindrical tanks were formulated in the 8 th decade of the 20th century. The metal tanks are designed to satisfy the requirements of limit states such as strength and stability of structures. The structure of each metal thin-walled vertical tank is different from the ideal design geometry. This is a result of manufacture and installation inaccuracies (Cosham \& Hopkins, 2004; Rasiulis, Samofalov, \& Šapalas, 2006; Kala, Gottvald, Stonis, \& Omishore, 2014; Christopher, 2017; Zhang et al., 2015).

The inaccuracies and tolerances are covered by the construction rules, norms and standards (American Petroleum Institute, 2012; European Committee for Standardization, 2007). The metal structures of tanks can be safely used for a long time if their design, fabrication, installation, corrosion protection, etc. are performed without errors and in accordance with the applicable standards and requirements. During the real maintenance, various defects of metal structures emerge.

Tanks for storage of products (oil, gasoline, diesel, fuel oil, fertilizer, etc.) are usually classified into the group of specific and potentially dangerous structures. A collapse of these structures can have catastrophic consequences. One of the most common cases of a sudden accident with tanks arises due to a fracture of joints (either between the wall and the bottom or the wall and the roof) under hydrostatic pressure. The fracture commonly begins at highest stress points. Mostly, such fracture occurs along the wall height at vertical welded joints. Afterwards, due to high radial stress level the crack spreads and the wall becomes flat. In most cases, these accidents take place during winter due

*Corresponding author. E-mail: gintas.sauciuvenas@vgtu.lt 
to low temperatures and high winds. Failure of even the smallest tanks filled with petroleum products may cause explosions and fire. Such failures result in significant hazards to agriculture and an environment. Damages can be from 100 to 200 times greater than the price of a tank terminal.

Aliphanov (2004) describes 91 cases of accidents in 65 tanks. The expert conclusions were taken into account in determining the main cause and secondary reason of tank fracture. One main cause and no more than two secondary reasons were considered. During the investigation, the major and minor causes of fracture were grouped as follow and assessed as main and ancillary reasons: shortcomings of design documents (14 and 6 cases of emergency, as appropriate), construction defects (38 and 31 accident cases, as appropriate), mistakes of maintenance (11 and 10 accident cases) and adverse effects ( 2 and 18 accident cases, respectively).

The following are considered as shortcomings of design documentation: the incorrectly chosen design data such as computational model, steel grade or wrong solutions of joints. In 12 out of 14 accident cases, the shortcomings of design documentation were determined and for other two cases - mistakes of computational model or calculations. The mistakes in maintenance are: increasing the load, breakdown of technological equipment, etc. Construction defects are: material defects, deformation of sheets during its transportation, exceeded limit values of deformations of the substructure, welding defects, mistakes of testing procedures, etc. While loading and actions can be: storm, low temperature, mechanical damage, etc. The investigation on failures of 65 tanks showed that the dominant reason for the failure is brittle metal - 63\% (41 cases out of 65 ). All other causes amounting to $37 \%$ are explosions and fires - 12.3\% (8/65), vacuum - 7.7\% (5 of 65 ), corrosion $-3.1 \%$ (2 of 65 ), storm $-1.5 \%$ ( 1 out of $65)$, settlement of substructure $-1.5 \%$ ( 1 of 65 ) and other causes $-10.9 \%$ (7 out of 65 ). The main causes of tank failure are structural defects ( 9 cases out of 41 ), poor grade of materials (13 cases out of 41 ), hardened areas ( 3 cases out of 41), and welding defects (16 cases out of 41).

Among other causes, a brittle fracture of structures is generally the final reason for accidents with tanks. However, there are other reasons, which affect brittle fracture of metal, such as stress concentration due to structural defects (incorrectly performed technological cut-outs, etc.), restraints of elastic deformations of the shell, low grade of metal (chemical composition, mechanical properties and structure of metal), plastic deformations (due to the impact loads, etc.), formation of cracks (due to corrosion and sudden cooling after the welding, etc.), and welding defects.

In Aliphanov (2004), 84 emergency cases with tanks are analysed. Reasons for the accidents are presented in Table 1 and Figure 1. The reasons for fracture were determined according to expert conclusions. Data presented in Table 1 demonstrate the main and secondary causes of the failures for each tank. In $70 \%$ of cases, failures occur due

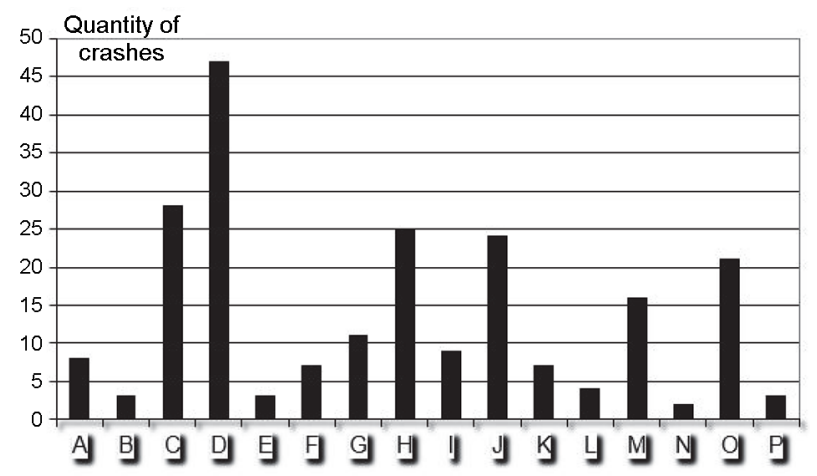

Figure 1. Diagram of tank crash causes (A - corrosive wear; B - local corrosion; C - low temperature; D - welding defects; E - shape defect; F - foundation defects, careen; G - vacuum, pressure difference; $\mathrm{H}$ - poor quality of steel; I - infringement of exploitation rules; J - infringement of the design; $\mathrm{K}$ - infringement of test rules; $\mathrm{L}$ - secondary crash; $\mathrm{M}$ - stress concentration; $\mathrm{N}$ - locked-up stresses; $\mathrm{O}$ - fire; $\mathrm{P}$ - loss of plasticity)

to several major and minor reasons (up to 6). Only $30 \%$ of tank failures occur due to one reason (Table 1). Among the main reasons, the most common were identified: low temperature $(C)$, welding defects $(D)$, low grade of steel $(H)$, discrepancies with the design (S), the stress concentration $(\mathrm{M})$, and fire $(\mathrm{H})$ (Figure 1).

In the light of the research-based results of tank failures, the defects of thin-walled sheet-metal structure and its deficiencies result in the decrease of strength and durability of structures or worsening of the maintenance features, which leads to increased maintenance costs. The defects may be classified as follow (Kandakov, Kuznecov, \& Lukijenko, 1994):

The first classification of defects: 1 . Visible surface open defects of structure uncovered by other structural elements, which may be detected by visual inspection; 2 . Invisible internal defects of structure or defects covered by protective layers, which may be detected by Nondestructive Testing (NDT) methods.

The second classification of defects: 1 . Corrosion of structure due to the aggressive environment, because of damages to protective layers or wrongly made waterproofing layers and protective layers of paints; 2 . Low grade of base metals (lower strength of steel, porosity, cracks, etc.); 3. Low grade of welds (lower strength of welds, porosity incomplete penetration, slag, notches, residual stress (Pasternak \& Kubieniec, 2016), cracks, wrong position of welds, the transverse and longitudinal deformations of welds, etc.); 4. Stress redistribution, additional strains due to the settlement of foundation, local buckling, etc.; 5. Stress concentration (at the places of cross-section changes of stiffeners, at the technological gaps or notches, connections, roughness, at the places of geometric defects such as sags, cambers, corrugations, cracks, etc.).

The third classification of defects: 1. "Sharp" defect is a local defect. In most cases, cracks in a material are 
Table 1. Causes of tank crashes
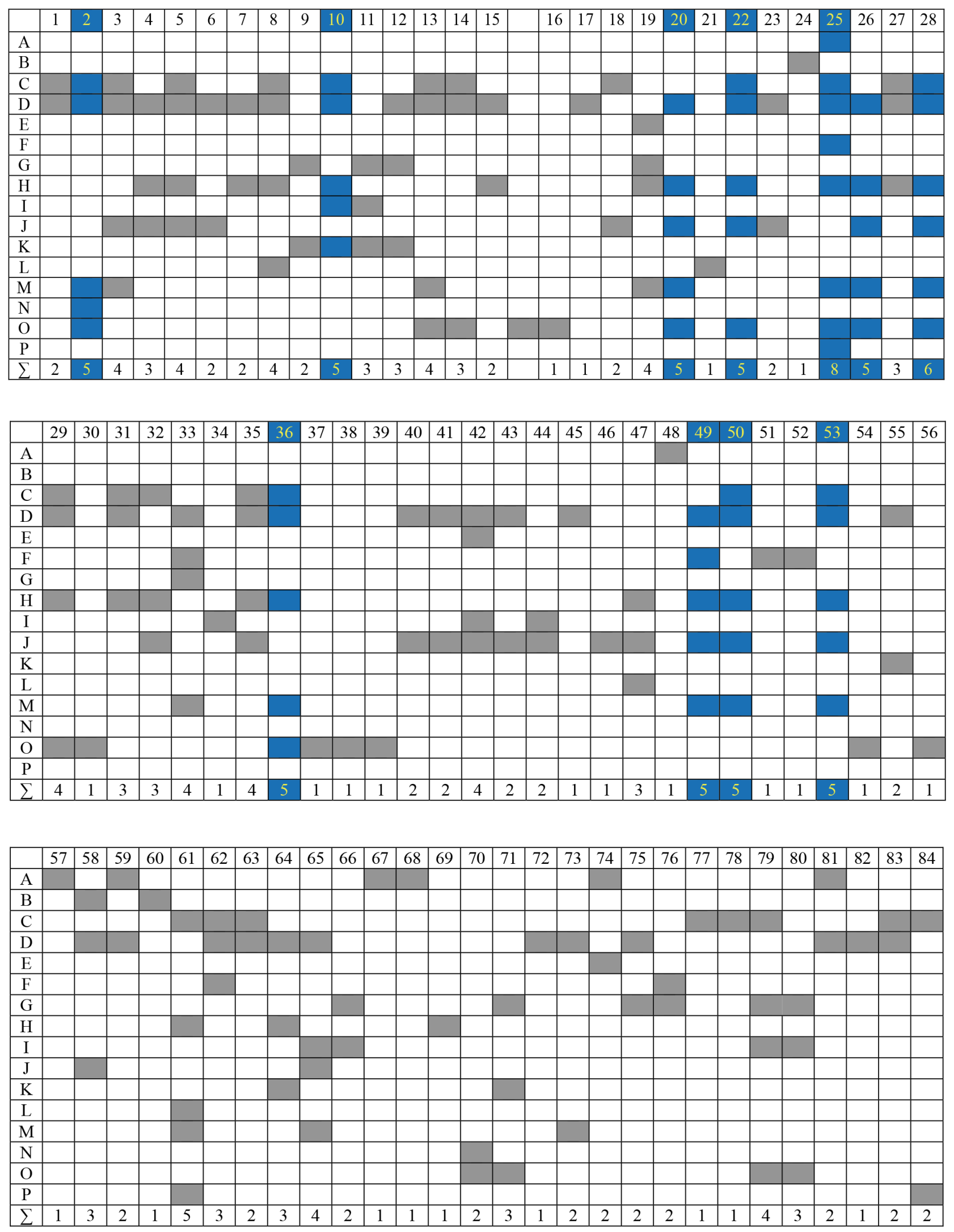
characterized by a sudden cross-section reduction, which causes a significant increase in stress compared to the nominal stress in the same place without the construction defect; 2. Geometric defects are local defects of structure geometry compared with the design geometry of a structure. They could change shape and affect the redistribution of stress or stress increase.

The steel corrosion, defects of welds, settlements of the foundation, stress concentration at stiffeners and the effect of cracks on the strength of structures are well explored in the scientific literature, which also suggests many methods for the prevention and assessment (Wang, Liew, \& Lee, 2015; Wang \& Zhou, 2015; Zhang et al., 2015). Meanwhile, the effects of geometric tolerances, sags, cambers and corrugations are not considered in greater detail. According to standards, there are two geometric parameters of defects, namely, the depth and radius of a defect; therefore, deviations from the common geometry of the structure, geometry peculiarities of defects and its location, the changes of mechanical properties of steel, etc. are not considered (Romanenko \& Samofalov, 2005).

Geometric tolerances, such as sags, appear due to welding stress at a mounting seam or at the places of manifold and tank connections (Aliphanov, 2004). Such sags have a "soft" geometric shape without sharp hogging.

Defects as a result of mechanical damage, usually are cone-shaped or rhombus (Aliphanov, 2004). The transition from a deviation to the undistorted surface of a structure is sharp with a small bending radius. There are more of other forms of geometric defects. In the cases of loss of stability or an accident, a number of geometric deviations may appear. Local geometric tolerances may be classified according to these features (Aliphanov, 2004): type (sags or cambers), cause (welding deformations, mechanical effects, and loss of stability), appearance in time (during manufacture, installation or maintenance), geometry (Romanenko, Samofalov, Šapalas, \& Aliphanov, 2004) (semiround, conical or semi-conical deviation), volume (single deviation, double deviation etc.), disposition (the single moment acting zone, the double moment acting zone, the stability zone).

\section{Geometry of the examined tank}

The present work analyses an existing aboveground cylindrical vertical tank with the volume of $5000 \mathrm{~m}^{3}$ (Figure 2). The tank is intended for storage of petroleum product bitumen. For a longer period, the tank is kept full. The pressure of the stored product is the predominant effect exerted on the cylindrical shell; therefore, the effect of wind load on the shell of the tank was not analysed. The number of load cycles of the tank is not great and does not exceed two times per year; therefore, the residual strain has no effect on the strength of the cylindrical shell of the tank. In the roof structure of the tank, valves remain open to avoid negative pressure on the tank shell during unloading.

The roof of tanks is supported on a central strut and wall. The roof is conical and made of steel sheets of different thicknesses (Figure 2(a)). The serviceable capacity of the tank is $4636 \mathrm{~m}^{3}$. The basic geometry of the storage: the height of the wall $\mathrm{H}=15.0 \mathrm{~m}$, the radius of the bottom strip of the central line of the wall $\mathrm{R}=10.46 \mathrm{~m}$, and the roof pitch $\mathrm{h}=1.3 \mathrm{~m}$. The plate thickness on the tank bottom in its central zone is $5 \mathrm{~mm}$ while the outside plates are $8 \mathrm{~mm}$. The tank wall consists of 10 sheets of different thicknesses (Figure 3(d)). From the bottom to the top, the determined wall thicknesses are $12.0 \mathrm{~mm}, 10.0 \mathrm{~mm}$, $9.0 \mathrm{~mm}$ and $7.9 \mathrm{~mm}, 6.9 \mathrm{~mm}$ and $5.8 \mathrm{~mm}, 5.9 \mathrm{~mm}$ and $5.8 \mathrm{~mm}, 5.9 \mathrm{~mm}$ and $6.0 \mathrm{~mm}$. The roof sheets are

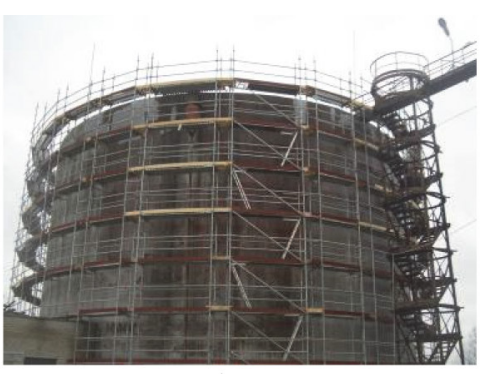

(a)

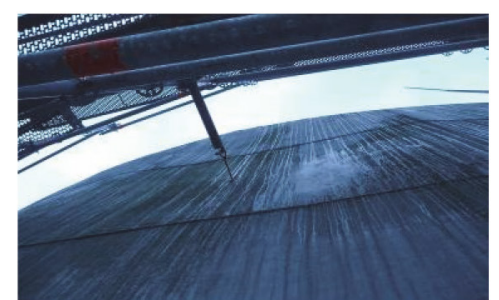

(d)

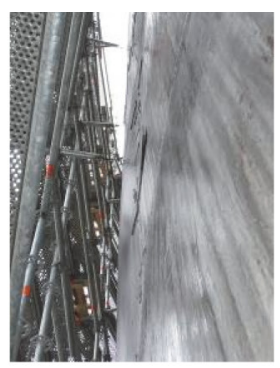

(b)

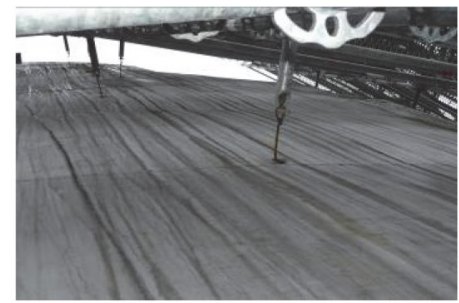

(e)

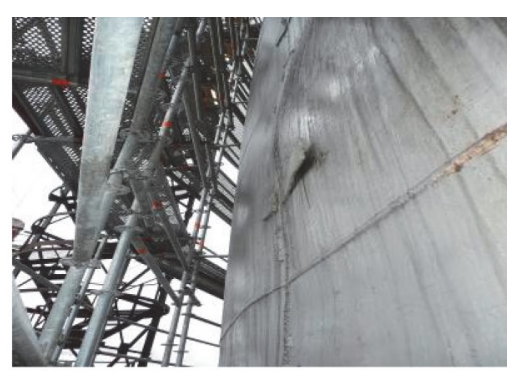

(c)

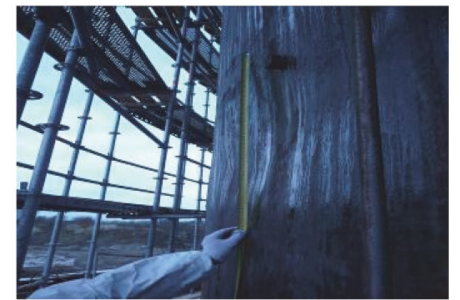

(f)

Figure 2. Object of investigation, a $5000 \mathrm{~m}^{3}$ tank: general view (a), geometrical local defect of the wall shell on the first mounting joint $(b, c)$, common geometrical defect of the upper wall shell (d), geometrical local defect of the wall shell on the second mounting joint (e), geometrical local defect of the wall shell next to the pipe of the fire system (f) 
Table 2. Defects of the tank shell geometry

\begin{tabular}{|c|c|c|c|c|c|c|c|}
\hline No. & $f$ & $r$ & $t$ & $R$ & $\gamma$ & $\beta$ & $\%$ \\
\hline 1 & -30 & 1690 & 5.9 & 10.46 & 5.1 & 6.8 & 1.8 \\
\hline 2 & -30 & 2200 & 5.8 & 10.46 & 5.2 & 8.9 & 1.4 \\
\hline 3 & -29 & 1100 & 6.0 & 10.46 & 4.8 & 4.4 & 2.6 \\
\hline 4 & -52 & 1660 & 5.8 & 10.46 & 9.0 & 6.7 & 3.1 \\
\hline 5 & -35 & 1840 & 5.9 & 10.46 & 5.9 & 7.4 & 1.9 \\
\hline 6 & -26 & 2280 & 5.8 & 10.46 & 4.5 & 9.3 & 1.1 \\
\hline 7 & -23 & 1450 & 6.9 & 10.46 & 3.3 & 5.4 & 1.6 \\
\hline 8 & +240 & 4370 & 5.8 & 10.46 & 41.4 & 17.7 & 5.5 \\
\hline 9 & -30 & 1390 & 6.9 & 10.46 & 4.3 & 5.2 & 2.2 \\
\hline 10 & -35 & 1800 & 5.9 & 10.46 & 5.9 & 7.2 & 1.9 \\
\hline 11 & -39 & 2300 & 6.0 & 10.46 & 6.5 & 9.2 & 1.7 \\
\hline 12 & -30 & 1260 & 6.9 & 10.46 & 4.3 & 4.7 & 2.4 \\
\hline 13 & -28 & 2140 & 5.9 & 10.46 & 4.7 & 8.6 & 1.3 \\
\hline 14 & -26 & 2660 & 5.8 & 10.46 & 4.5 & 10.8 & 1.0 \\
\hline 15 & -38 & 1410 & 6.9 & 10.46 & 5.5 & 5.2 & 2.7 \\
\hline 16 & -25 & 1870 & 6.0 & 10.46 & 4.2 & 7.5 & 1.3 \\
\hline 17 & -40 & 1450 & 5.9 & 10.46 & 6.8 & 5.8 & 2.8 \\
\hline \multicolumn{8}{|c|}{$\begin{array}{l}\text { Note: }-f-\text { the depth of the dent (Figure } 3(\mathrm{~d})) ;+f-\text { the depth of the bulge; } r-\text { the smallest distance between the points of } \\
\text { edges of the dent (bulge) or the minimal radius of the dent (bulge) (Figure } 3(\mathrm{~d}) \text { ); } R-\text { the radius of the tank; } \gamma(f, t)=\frac{f}{t}-\text { the } \\
\text { relative depth of the dent (bulge) to calculate by Eqn }(1) ; \hat{a}(r, R, t)=\frac{r}{\sqrt{R t}}-\text { the relative radius of the dent (bulge) to calculate } \\
\text { by Eqn (2); } \% \text { - the depth of the dent (bulge) expressed by percentage from the radius of the dent (bulge). }\end{array}$} \\
\hline
\end{tabular}

supported on radial beams. The cross-section of the radial beams is hot rolled single channel [ 300 . One end of beams is supported by the central strut and the other end - on the circumferential beams. The radial beams are connected together with annular beams (single channels [ $120 \times 60 \times 5$ and angles L63 $\times 6$ ). The cross-section of the central strut is a welded box section of two hot-rolled channels. The roof is made of steel sheet of various thickness. The thicknesses of the roof sheets (from the edge toward the centre of the roof) are $7.9 \mathrm{~mm}$ and $3.0 \mathrm{~mm}$ and $2.5 \mathrm{~mm}, 2.4 \mathrm{~mm}$, $2.6 \mathrm{~mm}$ and $2.6 \mathrm{~mm}$.

Different defects of various sizes were identified during an inspection. Examples of defects and deviations are shown in Figure 2. Figures 2(b) and 2(c) demonstrate sags with a smooth transition to swells at welded mounting. Another kind of a defect of the wall is shown in Figure $2(\mathrm{~d})$, i.e. the flatness of few sheets of walls. Another row of sags and swells is presented in Figure 2(e). The group defect was founded at the second seam of welded mounting. An example of a "sharper" local geometric defect is presented in Figure 2(f). 17 different size defects and geometric deviations were found. Location of defects and their geometry are shown in Figure 3 and Table 2. Defects No. 1-7 and 9-17 are sags. The depth of these defects from the design position of the wall are from $25 \mathrm{~mm}$ to $52 \mathrm{~mm}$. The depth of the sag No. 8 from the design position of the shell is $240 \mathrm{~mm}$.
The results of instrumental measures of the common deformation of the tank wall and its deviations from the original geometry showed that some of the defects are very significant. The wall radius deviation from the design geometry at wall height of $2.4 \mathrm{~m}, 7.5 \mathrm{~m}$ and $15.0 \mathrm{~m}$ are shown in Figure 4. The deviations of the tank diameter at the bottom strip are $75.0 \mathrm{~mm}$ and $146 \mathrm{~mm}$ at the top strip.

\section{Evaluation of the defect on the wall of the existing tank}

Standards for regulation of tank shell shapes have been developed in the United States, the Russian Federation, countries in Europe and elsewhere. Each country has different standards for various tolerances of local geometrical deviations (Table 3). In documents of the Russian Federation and Germany, tolerances of the shell geometry are conservatively limited. In these standards, local deviations from the shell geometry from the design position may not exceed $1.0 \%$ of the defect diameter (Table 3 and Figure 3(d)). The European standard gives higher values of tolerances, up to $1.6 \%$ related to the diameter of the defect. According to the European standard the tolerances of the shell surface roundness is classified as follows: class " $\mathrm{A}$ " is excellent quality, class " $\mathrm{B}$ " is a very good quality and class "C" is good quality (Table 3) (European Committee for Standardization, 2011). 


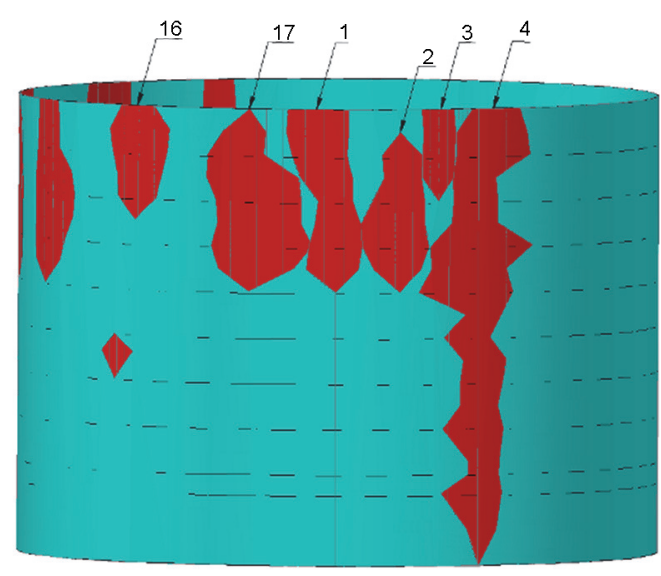

(a)

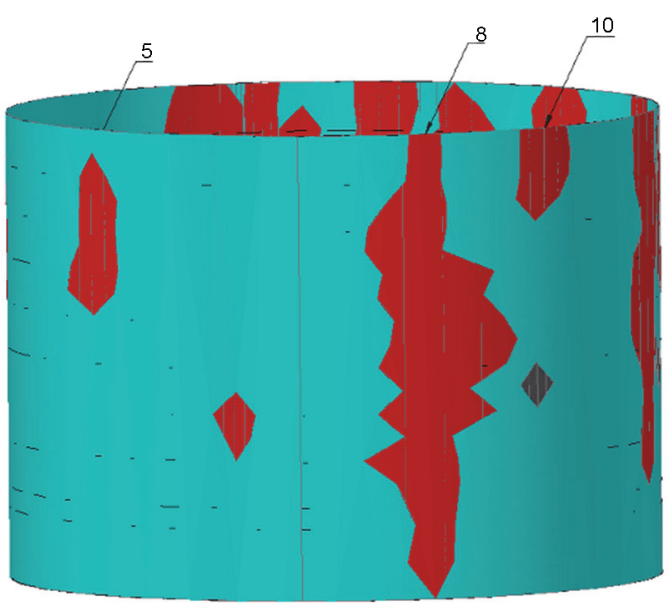

(c)

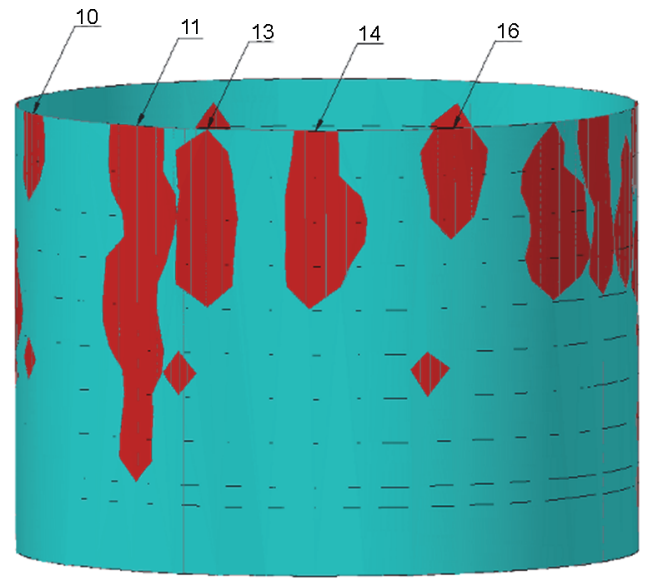

(b)

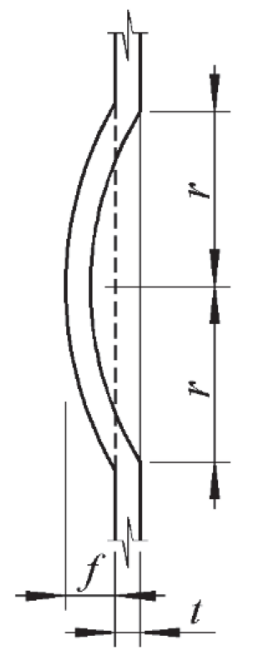

(d)

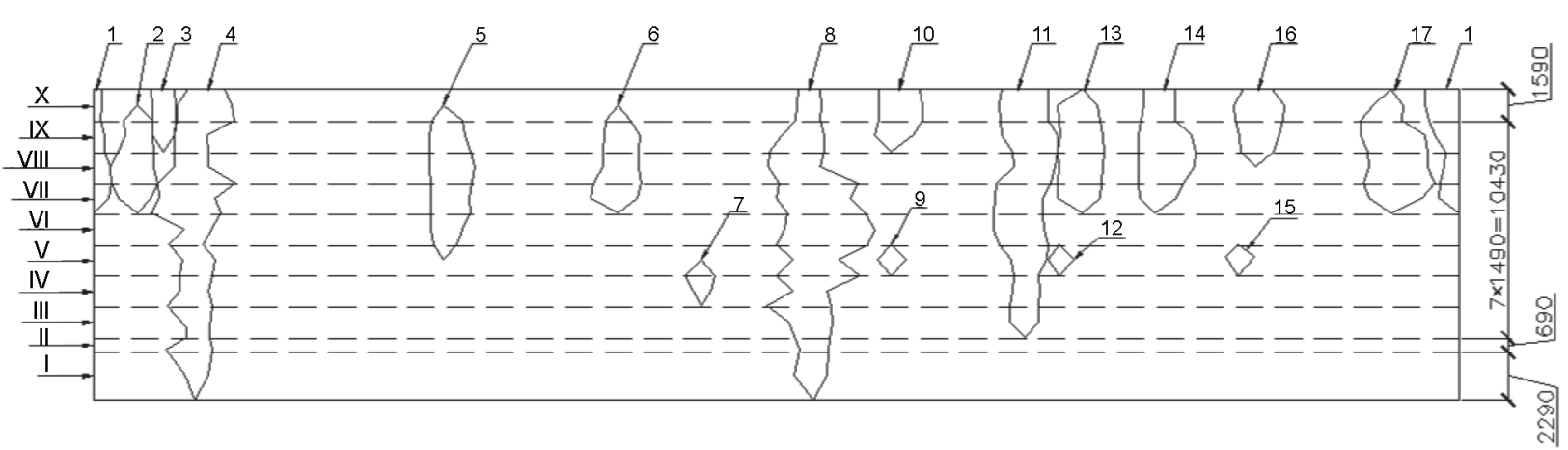

(e)

Figure 3. Layout of the local geometrical defects on the wall shell: egeneral views of the wall shell (a), (b), (c), the idealistic shape of the defect, the dent (d), the layout of the wall shell with the distribution of local defects (e)

The deviations of the existing tank are presented in chapter 2 and compared with permitted values of the European standard. According to the comparison, there is only one case where the deviation depth does not exceed $1.0 \%$ of the defect diameter (Table 2 and Figure 3). The depth deviation of 5 defects is between $1.0 \%$ and $1.6 \%$ (Table 2). In total, $64.7 \%$ of shell defect deviations are greater than allowed in the European standard (Table 2 and Table 3 ). In Table 2, they are marked in bold. The common tolerance of the existing tank shell was checked in accordance with the following expression (European Committee for Standardization, 2011):

$$
\Delta=\frac{d_{\max }-d_{\min }}{d_{\text {nom }}} .
$$

The shell geometry deviation of the existing tank at the height of $2.4 \mathrm{~m}$ above the bottom is $\Delta=0.007$, at $7.5 \mathrm{~m}-\Delta=0.002$, and at $15.0 \mathrm{~m}-\Delta=0.002$. The 
Table 3. Allowable imperfections depend on the design code

\begin{tabular}{|l|c|c|}
\hline \multicolumn{2}{|c|}{ Standard } & Allowance \\
\hline \multirow{2}{*}{ EN 1090-2: 2008+A1:2011 (2011) } & A & $f \leq 0.6 \%$ \\
\cline { 2 - 3 } & B & $f \leq 1.0 \%$ \\
\cline { 2 - 3 } & C & $f \leq 1.6 \%$ \\
\hline ANSI/API STD 650 (2012) & & $f \leq 1.4 \%$ \\
\hline STO 0030-2004 (2004) & & $f \leq 1.0 \%$ \\
\hline DIN 18800-4:2008-11 (2008) & $f \leq 1.0 \%$ \\
\hline
\end{tabular}

presented deviations do not exceed the permitted deviation for the class "A" $(\Delta \leq 0.007)$ and are denoted as "excellent quality of the shell" The analysis of common and local defects shows that further research is necessary to assess the effects of local deviations on the load bearing capacity and the operating period.

\section{Numerical model}

The numerical model of the investigated tank of 5,000 $\mathrm{m}^{3}$ was prepared using the standard FEA program "SolidWorksSimulation". The linear and non-linear calculations of tank and its fragments were executed. An ideal

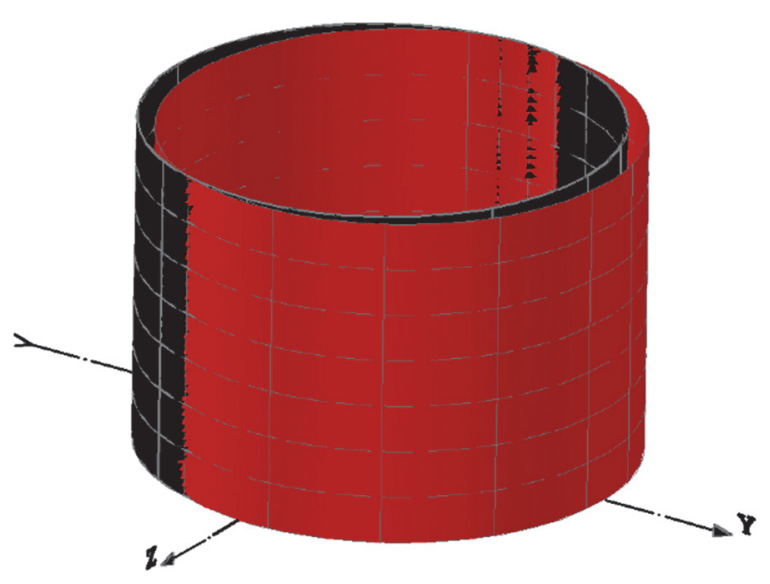

(a) geometry of the tank and its discreet model are presented in Figure 5. The discrete model of tanks with local defects and the general view specular to the discreet model are shown in Figure 6. For modelling of the tank shell, "SHELL3" type thin-walled elements with three nodes were used. Each node is described with six degrees of freedom: three directions of displacements and three rotations. The $50 \mathrm{~mm}$ finite elements on the defect place were used. Relevance of shell elements application in steel tank modelling was tested in article of Romanenko and Samofalov (2005) related to FEM model sensitivity analysis. For modelling of the roof-supporting beams, "BEAM3D" type elements with two nodes were used. The tank was modelled on the elastic base: on a concrete surface with the rigidity of $20,000 \mathrm{kPa} / \mathrm{m}$. The connection joint between roof and wall is hinge. One of the main loading assessed in the tank calculation was the hydrostatic pressure of the stored product boiler oil. The density of the boiler oil weight was $11.0 \mathrm{kN} / \mathrm{m}^{3}$. The following mechanical properties of steel were used in the tank calculations:

- characteristic value of the yield strength $f_{y}=255 \mathrm{MPa}$;

- characteristic value of the tensile strength $f_{u}=380 \mathrm{MPa}$;

- strain value at the yielding point $\varepsilon=0.0012$;

- strain value at the tensile strength point $\varepsilon=0.5$.

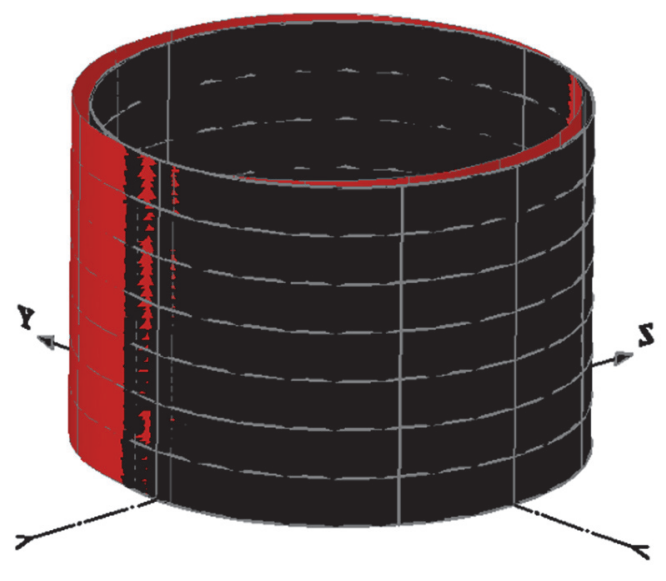

(b)

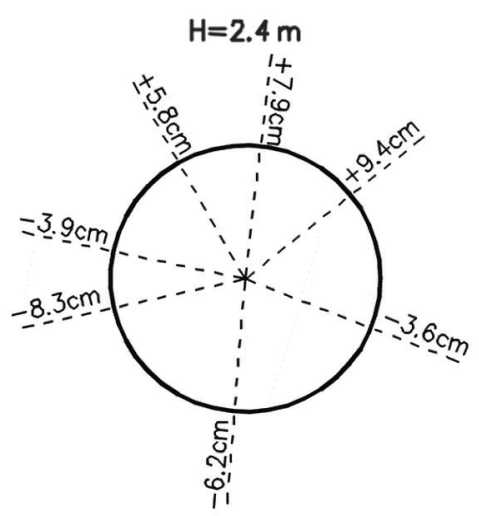

(c)

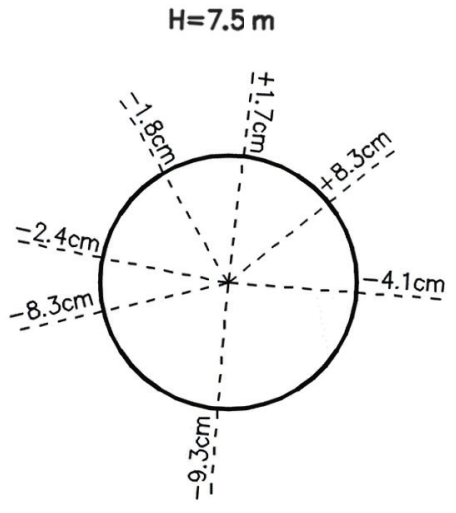

(d)

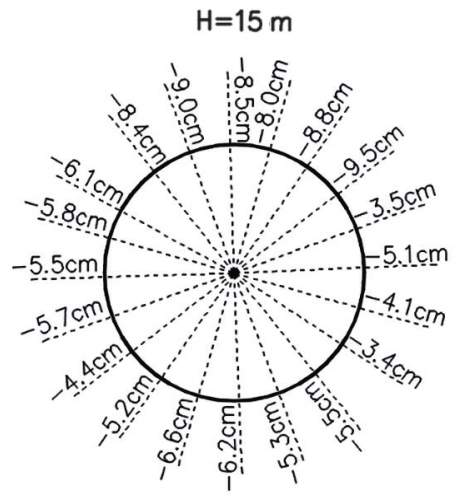

(e)

Figure 4. Layout of the common geometrical defects on the wall shell: general views of the wall shell (a), (b), common tolerances of the wall shell (c), (d), (e) 


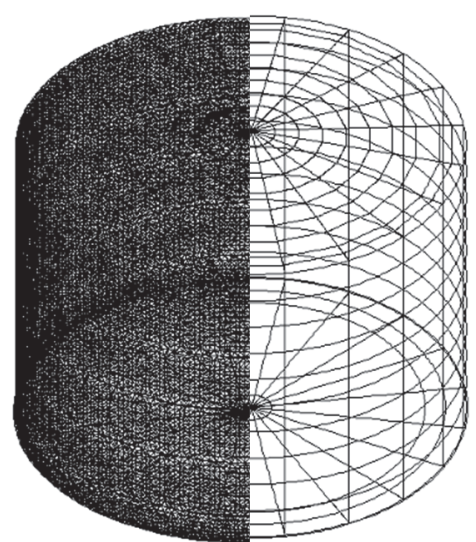

(a)

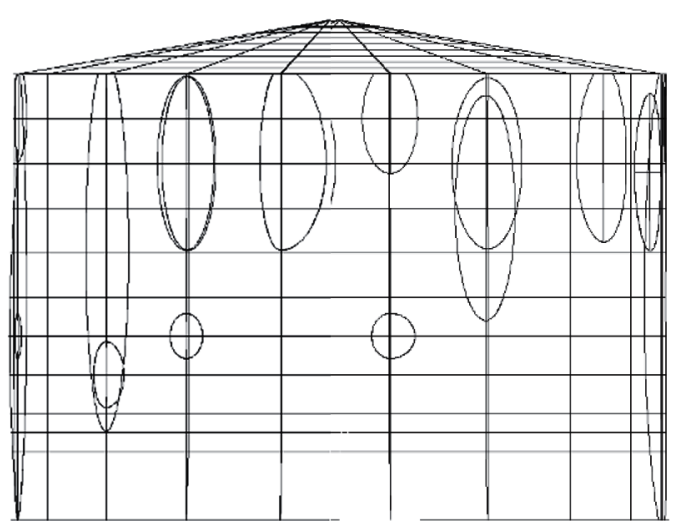

(b)

Figure 5. Discrete model of the tank (a), general view of the tank model (b)

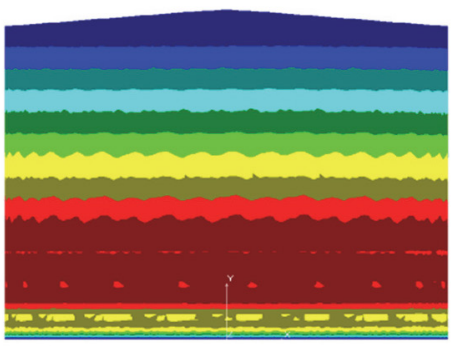

(a)

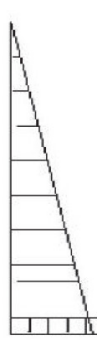

(b)

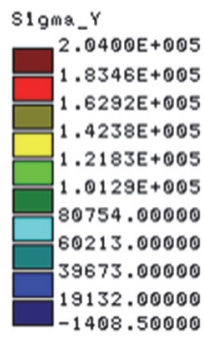

(c)
Figure 6. Distribution of the circumferential stresses on the tank wall when the pressure of the stored product is applied; black oil (a), pressure diagram of the stored product (b), values of the stresses, $\mathrm{kPa}(\mathrm{c})$

\section{Calculation results}

The calculation results of the regular cylinder geometry tank under the pressure of the stored product are presented in Figure 6. Figure 6(b) presents the diagram of the internal pressure rising from the top to the bottom and related with the radial stress of the tank shell (Figure 7(a)). The max stress at the bottom strip of the shell (Figure $7(\mathrm{c})$ ) is less than the yield strength of steel $\sigma_{y}=204 \mathrm{MPa}<f_{y}=255 \mathrm{MPa}$.

Figure 7 shows the calculation results of the first order analysis of the tank with deviations under the pressure of the stored product. The charts present the distribution of the equivalent stress. The stress range in the charts is chosen from 0.0 MPa to the steel tensile strength limit of the wall, $f_{u}=380 \mathrm{MPa}$. The theoretical equivalent stress distribution shows increase in the stress at sags and swells. For larger size defects (defects No. 4, 8, 11) or a group of defects (the first group of defects: $8,9,10$, defects of the second group: $11,12,13$ and the third group of defects: 1 , $2,3,4)$, the stress concentration covers the entire defect area. Those defects and their groups may be attributed to

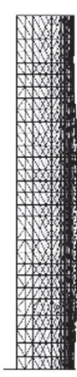

(a)

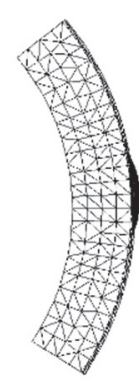

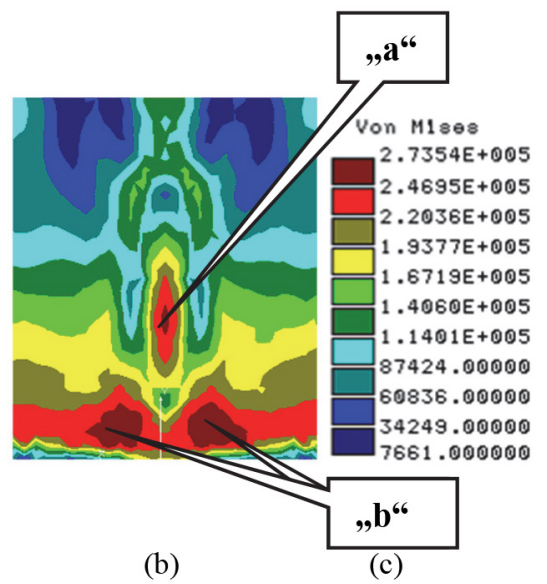

(b)

(c)
Figure 7. Part of the wall shell with the geometrical defect when storing the product, black oil, pressure: discrete model of the part of the wall of the tank (a), the distribution of the

Von Mises stresses (b), values of the stresses, $\mathrm{kPa}$ (c)

common defects. Single defects have a clear layout of extreme points, i.e. the central zone and the contour points of defect (Figure 7(b)). Maximum stresses in the defect area are higher than the steel yield strength $\sigma_{y}>f_{y}=255 \mathrm{MPa}$. Further, this work analysed the effects of single defects on the behaviour of the tank wall. The FEA models of the shell with single defects are shown in Figures 8 and 9. The discrete model of the shell segment with the defect No. 8 and the calculation results are shown in Figure 8. The second order analysis was carried out taking into account the physical and material non-linearity and bi-linear stress/ strain curve. As the result, a decreased stress was noted in comparison with the first order calculation results of the entire model (Figures 7 and 8). The highlighted places of the significant stress concentration were at the central part of the defect (the point "a") and the edges of the defect in the transition zone with the min bending radius (the points "b") (Figure 8). The maximum stresses in the defected area remain $6.8 \%$ higher than the yield strength of steel, 


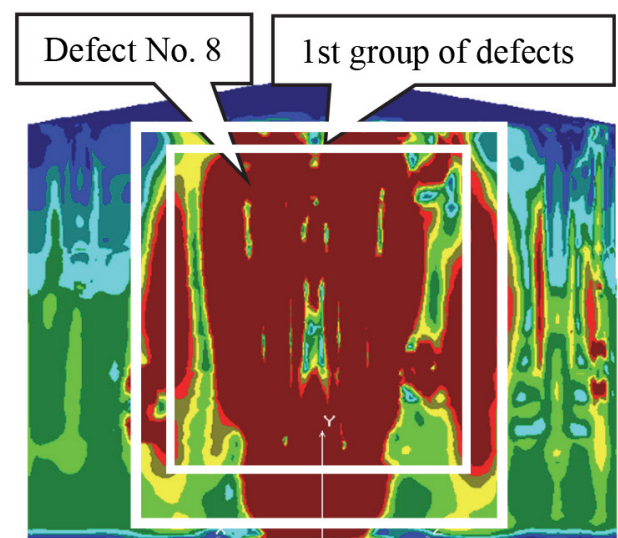

(a)

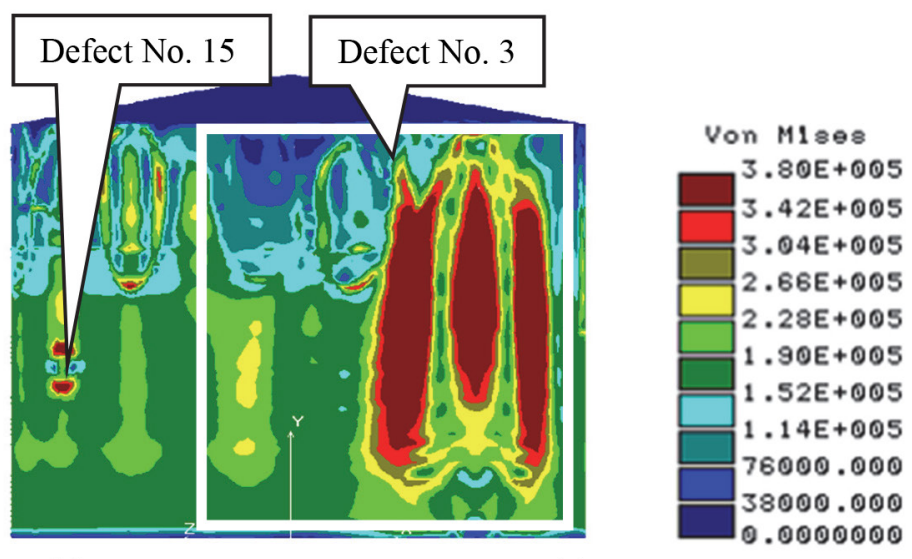

(b)

(c)

Figure 8. Distribution of the Von Mises stresses on the wall shell with geometrical defects with pressure of the stored product on the wall: the layout of the tank and the diagram from $0^{\circ}$ to $180^{\circ}$ (a), the layout of the tank and the diagram from $180^{\circ}$ to $360^{\circ}$ (b)

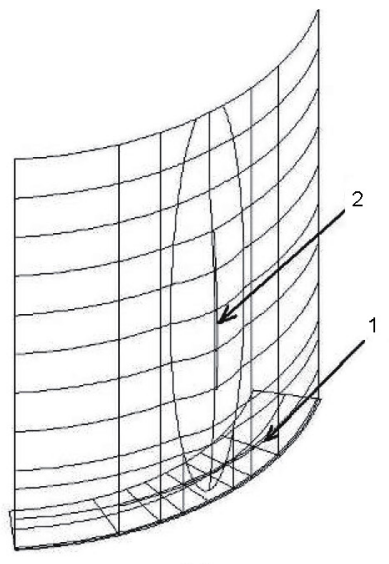

(a)

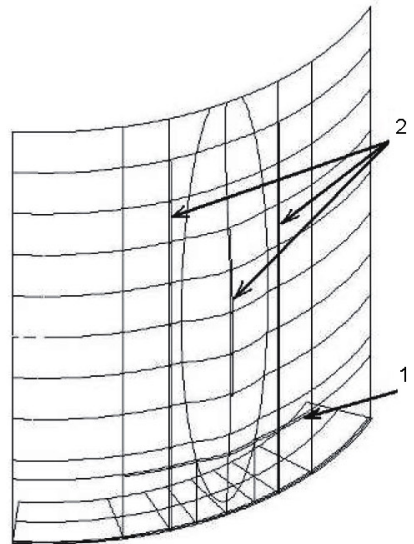

(b)

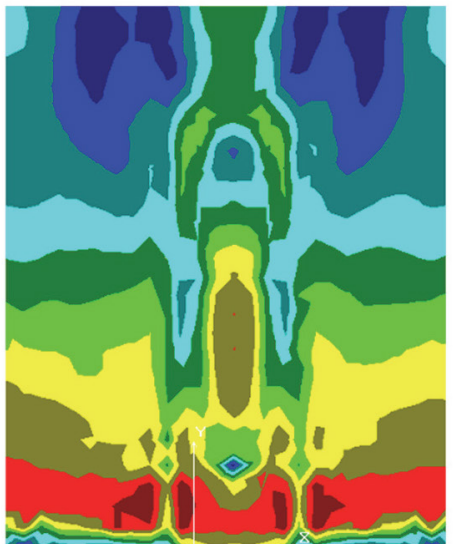

(c)

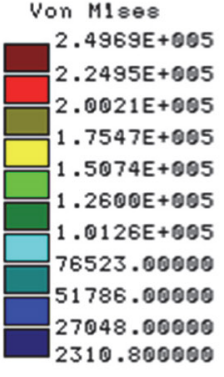

(d)

Figure 9. Part of the tank with the strengthening scheme: the first variant of the strengthening (a), the second variant of the strengthening (b), 1 - the circular reinforcement plate, 2 - the meridian reinforcement plate, distribution of the Von Mises stresses on the wall shell (c), values of the stresses, $\mathrm{kPa}(\mathrm{d})$

$\sigma_{e q}=273,5 \mathrm{MPa}>f_{y}=255 \mathrm{MPa}$. The stress concentration factor at the point " $b$ " is equal to:

$$
k_{\sigma, b}=\frac{\sigma_{k, b}}{\sigma_{n o m}}=\frac{273.5}{204.0}=1.34 .
$$

The stress concentration factor at the point "a" is:

$$
k_{\sigma, a}=\frac{\sigma_{k, a}}{\sigma_{n o m}}=\frac{273.5}{183.5}=1.49,
$$

where: $\sigma_{k, a}, \sigma_{k, b}$ - the stress concentration factor at the points "a" and "b", respectively; $\sigma_{\text {nom }}$ - the nominal stress of the ideal geometry shell.

Figure 9 shows two cases of shell reinforcement, i.e. with the meridian stiffeners and annular stiffeners that are designed. The thickness, width and length of the meridian stiffener appropriately is $t=14 \mathrm{~mm}, b=100 \mathrm{~mm}$, $L=5860 \mathrm{~mm}$. The thickness, width and length of the annular stiffener appropriately is $t=10 \mathrm{~mm}, b=100 \mathrm{~mm}$, $L=6400 \mathrm{~mm}$. "SHELL3" finite elements were used for stiffeners modelling. The calculation results of the last fragments of the shell with defects and reinforcement are presented in Figures 9(c) and 9(d). The fragments of the shell also were loaded with pressure of the stored product. The calculation was carried out using the second order method. According to the distribution equivalent stresses, both of strengthening methods are available to reduce the stress concentration in places of defects. The stresses in the defect zones are less than the yield strength of steel. In the first case of strengthening, the stress decreased by $19.2 \%$ in comparison with the shell stress of the non-strengthened shell.

The second method of strengthening is less effective although the number of stiffeners is higher. The stress reduction is only 9.5\% $\left(\sigma_{y}=249.7 \mathrm{MPa}<f_{y}=255 \mathrm{MPa}\right)$. The first method for the strengthening of "a" and " $b$ " zones allows reducing the effective stress concentration more effectively. 


\section{Conclusions}

The analysis of reasons for tank fracture and the numerical analysis of the existing tank of $5000 \mathrm{~m}^{3}$ in volume allow drawing the following conclusions:

1. The factor of stress concentration takes the leading position (position 6) among the reasons for tank fracture. On the other hand, the deviation of the tank geometry and smooth local defects make a secondary influence on the load-bearing capacity of the shell structures. For this reason, local defects should be classified in detail as well as proposed at the end of the first chapter.

2. If the distance between defects is small, they should be examined as a group and not as a single defect.

3. Smaller single defects have clear location zones of stress concentration - the circumference of a defect and its inner zone.

4. The stress concentration zones of larger defects have an inner defect zone and a transition zone with a smaller radius.

5. The area of stress concentration of a group of defects covers the whole defective zone.

6. In order to effectively reduce the stress concentration of the strengthening elements, they should be located in places under the greatest stress.

\section{Author contributions}

Antanas Šapalas, Gintas Šaučiuvėnas Konstantin Rasiulis Mečislovas Griškevičius and Tomas Gečys conceived the study. Antanas Šapalas, Gintas Šaučiuvènas and Konstantin Rasiulis were responsible for data collection, processing, and analysis. Mečislovas Griškevičius and Tomas Gečys wrote the paper.

\section{Disclosure statement}

The authors declare that they do not have any competing financial, professional, or personal interests from other parties.

\section{References}

Aliphanov, L. A. (2004). Regulation of the shape defects and resources of the vertical cylindrical tanks ( $\mathrm{PhD}$ thesis). Architectural-Building Academy.

American Petroleum Institute. (2012). Welded steel tanks for oil storage (ANSI/API STD 650, $11^{\text {th }}$ ed.). Americal national standard.
Christopher, T. M. (2017). The failure investigation of fuel storage tanks weld joints in Tanzania. International Journal of Mechanical Engineering and Technology, 8(4), 128-137.

Cosham, A., \& Hopkins, P. (2004). The effect of dents in pipelines-guidance in the pipeline defect assessment manual. International Journal of Pressure Vessels and Piping, 81, 127-139. https://doi.org/10.1016/j.ijpvp.2003.11.004

Deutsches Institut für Normung. (2008). Steel structure - Part 4: Stability - Analysis of safety against buckling of shells (DIN 18800-4:2008-11). German Standard.

European Committee for Standardization. (2007). Eurocode 3 Design of steel structures - Part 1-6: Strength and stability of shell structures (EN 1993-1-6:2007).

European Committee for Standardization. (2011). Execution of steel structures and aluminium structures - Part 2: Technical requirements for steel structures (EN 1090-2: 2008+A1:2011).

Kala, Z., Gottvald, J., Stonis, J., \& Omishore, A. (2014). Sensitivity analysis of the stress state in shell courses of welded tanks for oil storage. Engineering Structures and Technologies, 6(1), 7-12. https://doi.org/10.3846/2029882X.2014.957899

Kandakov, G. P., Kuznecov, V. V., \& Lukijenko, M. I. (1994). Analysing of the crash causes of the vertical cylindrical tanks. Pipeline Transportation, 5, 15-16.

Pasternak, H., \& Kubieniec, G. (2016). Implementation of longitudinal welding stresses into structural calculation of steel structures. Journal of Civil Engineering and Management, 22(1), 47-55. https://doi.org/10.3846/13923730.2014.994029

Rasiulis, K., Samofalov, M., \& Šapalas, A. (2006). Stress strain state investigation of soft defects on the thin steel plate by using experimental method. In Proceedings of the $11^{\text {th }}$ International Conference "Mechanika" (pp. 283-288).

Romanenko, K., \& Samofalov, M. (2005). Analyze and estimation of the soft defects on the thin wall tankages. In Proceedings of the $10^{\text {th }}$ International Conference "Mechanika" (pp. 17-23).

Romanenko, K., Samofalov, M., Šapalas, A., \& Aliphanov, L. A. (2004). Linear and physical non-linear stress state analysis of local shape defects on steel cylindrical tank walls by the finite element method. Mechanika, 46(2), 5-13.

Wang, Y., \& Zhou, H. (2015). Numerical study of water tank under blast loading. International Journal of Impact Engineering, 90, 42-48. https://doi.org/10.1016/j.tws.2015.01.012

Wang, Y., Liew, J. Y. R., \& Lee, S. C. (2015). Structural performance of water tank under static and dynamic pressure loading. International Journal of Impact Engineering, 85, 110-123. https://doi.org/10.1016/j.ijimpeng.2015.06.018

ZAO CNIIPSK im. Mel'nikova. (2004). Vertical cylindrical steel tanks for petroleum and petroleum products. Rules of technical diagnosing, repair and reconstruction (STO 0030-2004). Russian standard (in Russian).

Zhang, Z., Hui, P., Gu, C., Xu, P., Wu, Y., \& Hua, Z. (2015). Buckling of cold-stretched cylindrical vessels under external pressure: Experimental and numerical investigation. International Journal of Impact Engineering, 131, 475-486. 